\title{
A Comparative Study of the Use of Conjunctions and References in Electronic Mails vs. Paper- based Letters
}

\author{
Nader Assadi Aidinlou \\ Department of ELT, Ahar Branch, Islamic Azad University, Ahar, Iran \\ Elnaz Reshadi (corresponding author) \\ Department of ELT, Ahar Branch, Islamic Azad University, Ahar, Iran
}

\begin{abstract}
The present study set out to compare the use of conjunctions and references in electronic mails and paper-based letters produced by Iranian EFL learners. Based on this purpose, the researchers used a mixed methods research and selected a sample of 54 university students majoring in English Language Translation. All the participants were asked to write a letter in a paper-based method. After two weeks, the same participants produced letters in the form of electronic mails. After data collection sessions, the researchers compared the two sets of data on the basis of the use of three types of conjunctions, i.e. coordinating, correlative and transitional conjunctions and also three types of references, i.e., anaphoric, exophoric and cataphoric. Actually, the researchers used Paired-samples t-test to estimate the amount of conjunctions used in electronic emails and paper-based letters. They, further, used the same statistical test to analyze the use of references in the two mediums of letter writing. In contrast to the use of conjunctions which presented a statistically significant difference, the use of references was not significantly different in electronic mails and paper-based letters. The research findings have several implications for language instructors and university students.
\end{abstract}

Index Terms - electronic mails, conjunctions, references, paper-based letters

\section{INTRODUCTION}

In ordinary contexts of language use, language can be considered as a written or spoken discourse and can be used as a means of communication. Recently, such communication took several forms one of which was computer-mediated communication (CMC). Warschauer (1996) believes that CMC involves the use of the computer as a tool, rather than as a deliverer of instructional material. He claims that this writing type provides a less threatening means of communication. Such explanations highlight the issue that computer assisted writing involves some levels of communication and doing something with the language. According to Danet (2002) electronic mail is one of the most popular applications of online digital technologies and as a new means of communication become truly widespread. This widespread use of emails was in contrast with the letters that were written using a pen and paper.

Whatever the mood of writing, either electronic or paper-based, writers need to attend to a series of steps while producing a written text. According to Seow (1995), there are a number steps responsible for process writing. He calls the first step planning and assumes it as a step in which the learners are asked to generate and brain storm ideas about the topic. As mentioned by Seow (1995), the second step is drafting and it is responsible for motivating learners to start writing. This step requires the learners to make an attempt to put their ideas on paper. After drafting, the writers need to revise their written text by focusing on detailed organization of the ideas. This stage is of great importance to this paper since it is at this stage which learners are able to use their cohesive ties more effectively. Cohesive ties, as stated by Nunan (1993), are devices that distinguish a text from random sentences. Halliday and Hasan (1976) classify such grammatical and lexical connection into five categories: reference, substitution, ellipsis, conjunction, and lexical ties. Learners' knowledge of cohesive ties can boost their ability to revise what they have written. The last step is to edit the text for grammar, spelling and punctuation (Seow, 1995).

The complexity of any discourse including discourse of emails and paper-based letters has been the subject of discussion during the last decades (McCarthy 199). According to Crystal (1992, cited in Nunan, 1993) discourse is a continuous stretch of language larger than a sentence, often constituting a coherent unit, such as a joke or narrative. One way of establishing such a relationship is using cohesive ties and creating cohesion.

As pointed earlier, there are five types of cohesive ties. Richards et al (1992) consider references as words or phrases which relate an utterance to a time, place or person in a direct way. In English, reference items involve pronouns, demonstrative, the article the and the items like such a (McCarthy, 1991). McCarthy (1991), further, classifies references as anaphoric reference, exophoric reference and cataphoric reference. Substitution is the second set of 
cohesive ties. According to Salkie (1995), substitutions are special words which can contribute to cohesion by replacing words in the text with some other words such as one, do, and so that have already been used.

According to Nunan (1999), conjunctions link the elements of one or more sentences together and are of three types: coordinating, correlative and transitional. Also conjunctions are defined by Er (1993) as semantic connection between clauses.

Ellipsis is the other type of cohesive tie and refers to a structural element that is omitted from a text (Nunan, 1993). The last cohesive tie is lexical ties or relations and as stated by Eggins (1994) are concerned with how the writer or speaker uses lexical items such as nouns, verbs, adjectives or adverbs and also chain of clauses to relate the text consistently to its area of focus.

Several studies have been conducted to investigate the relationship between electronic texts in general and writing performance as well as the elements involved in written texts (Slutsky \& Sardegna, 2010; Sattar and Nahrkhalaji, 2012; Lightfoot, 2006; Biesenbach-Lucas and Weasenforth, 2001; Biesenbach-Lucas et al 2000).

Slutsky and Sardegna (2010) studied how web-based writing materials could promote non-native business students' autonomous learning. Their paper described the collaborative development of a web-based business writing handbook designed to address the specific needs of international business students. The handbook provided the students with an opportunity to gain awareness of common ESL business writing errors and gave them strategies for finding and correcting those errors. This study revealed a self-directed language learning strategies investment.

Also, the relationship between emails and writing progress has been studied in EFL context. In a study, Sattar and Nahrkhalaji (2012) studied the role of email activities in EFL writing classes. After requiring the learners to complete a number of writing assignment in the form of emails, the researchers examined the effect of such activates on learners' writing performance. They reported that the participants in this group did the same as learners in the conventional writing class.

Furthermore, in a comprehensive study, Lightfoot (2006) compared elements of e-mails and face to face communication in an educational environment. They administered a survey with 596 undergraduates and reported that students usually care more about email communication with the instructor and groups of peers than they do for equivalent face-to-face communication. Moreover, students tend to put about the same amount of thought into e-mail compared to verbal communication while working with individual peers.

Biesenbach-Lucas and Weasenforth (2001) studied the effect of medium, i.e. email and word-processing, on the message. The researchers examined the written messages of some intermediate non-native students for differences in use of cohesive features, length of text produced in each medium, and differences in text-initial contextualization. In the case of the use of cohesive ties, the two mediums showed no difference. However, results indicated a difference in the case of length of the text and text-initial contextualization. In a rather related study, Biesenbach-Lucas et al (2000) studied the use of cohesive features in ESL students' email and word-processed texts. The results showed that both cohesive features and text length differentiated email and word-processed writing.

Since most Iranian EFL contexts do not posses Computer Assisted Language Learning (CALL), it seems that the learners may face some difficulties in producing coherent texts while using computers as a medium of communication. The difficulty may even become much crucial when the learners are asked to write emails. In this case, they are interacting with a real audience and this may cause some barriers in using cohesive ties in their emails. The major challenge of the present paper was to investigate the use of two types of cohesive ties used in electronic mails versus paper-based letters in advanced university students. That is, the researchers tried to examine the frequency and type of use of conjunctions and references in emails and paper-based letters produced by English Language Translation students. In other words, the researchers' main concern was to compare the use of three types of conjunctions including coordinating, correlative and transitional conjunctions as well as three types of references, i.e., anaphoric, exophoric and cataphoric in electronic mails versus paper-based letters. For this purpose, the following research questions were posed:

1. Is the amount of conjunctions different in electronic mails and paper-based letters?

2. Is the amount of references different in electronic mails and paper-based letters?

3. Which conjunctions are common in electronic mails?

4. Which conjunctions are common in paper-based letters?

5. Which references are common in electronic mails?

6. Which references are common in paper-based letters?

\section{METHOD OF THE STUDY}

Design

In order to address the research questions of this study, the researcher used a mixed method research. The reason for choosing a mixed method research was the need for quantifying the amount of cohesive ties at data analysis stage and also investing the type of three types of conjunctions, i.e. coordinating, correlative and transitional conjunctions and three types of references i.e., anaphoric, exophoric and cataphoric in electronic mails and paper-based letters.

\section{Participants}

This study was an attempt to examine Iranian EFL learners' use of two types of cohesive ties, i.e. conjunctions and references in electronic mails and paper-based letters. As the participants were aimed at producing letters, it was a good 
idea to choose those who were taking letter writing course. For this reason, 59 English Language Translation students from Payam-Noor University of Iran participated in this study. The age range of the participants was 18- 42 (mean 30) and they were 41 female and 18 male participants. Five of the participants were eliminated from the study because they did not complete the letter writing tasks as they were required.

\section{Instruments}

This study required the use of a two-fold instrument. In other words, the researchers used two distinct mediums of writing letters. The first medium was writing letters using paper and pencil. In contrast, the second medium involved the use of computers for writing letters in the form of emails.

\section{Procedures}

The researchers of this paper collected data from a group of English Language Translation students who were attending a letter writing course in Payam-Noor University of Iran. It is important to note that the participants were learning letter writing in a conventional rather than CALL context. The researcher decided that it would be best not to inform the participants of the fact that they were taking part in a research to prevent the probable influences on the participants' performance.

The first step in data collection procedure was to ask the participants to write a letter to their teachers. At this stage, the participants wrote a paper-based complaint letter titled "complain about a mistake by the bank". After two weeks, the second step in data collection started by requesting the participants to write an email to their instructor. The title of this electronic based letter was not same but was parallel to paper-based letter's title to avoid the probable practice effect. As a result the researchers selected "complain about damaged merchandise" as the title of this electronic letter (electronic mail). Meanwhile, it is important to restate that five participants were omitted from the study for their incomplete participation.

After collecting the second group of data, the researchers compared the two sets of data on the basis of the use of three types of conjunctions and references. For the purpose of comparison, they made use of Halliday and Hassan's (1976) classification of conjunctions and references. Moreover, they adopted a method of anticipating the cohesive ties density proposed by Halliday and Hassan (1976). According to this method, the researchers needed to count the mean number of cohesive ties per T-unit. Finally, the researchers used Paired-samples t-test to estimate the amount of conjunctions used in paper-based letters and electronic emails. They, further, used the same statistical test to analyze the use of references in the two types of letters.

\section{RESULTS}

As mentioned before, the researchers used Halliday and Hassan' (1976) classification to estimate the number of conjunctions and references produced by the participants both in electronic mails and paper-based letters. In order to estimate the significance of the differences of the two sets of means, the researchers made use of Paired-samples t-test.

In Table 1, we can see that conjunctions present a lower mean score for electronic mails than paper-based letters $(1.07$ < 1.32). Moreover, this table displays lower degree of mean in the use of references for electronic mails. In fact, the mean score for the use of references in electronic mails is 1.13 which is lower than the mean score for paper-based letters which is 1.24 . The major questions of this research were whether these differences were significant or not.

TABLE 1.

STATISTICS FOR THE USE OF CONJUNCTIONS AND REFERENCES IN ELECTRONIC MAILS AND PAPER-BASED LETTERS

\begin{tabular}{|ll|l|l|l|l|}
\hline & & Mean & $\mathrm{N}$ & Std. Deviation & Std. Error Mean \\
\hline Pair 1 & Conjunctions in electronic mails & 1.0778 & 54 & .66038 & .08987 \\
& Conjunctions in paper-based letters & 1.3278 & 54 & .33332 & .04536 \\
Pair 2 & References in electronic mails & 1.1370 & 54 & .56076 & .07631 \\
& References in paper-based letters & 1.2444 & 54 & .41694 & .05674 \\
\hline
\end{tabular}

The researchers have carried out a paired-samples t-test to compare two sets of scores (number of conjunctions and references in electronic mails and paper-based letters) obtained from the same group $(\mathrm{N}=54)$. It is important to note that this statistical test has been conducted for both conjunctions and references. For the use of conjunctions, there was a significant difference in scores for electronic mails $(\mathrm{M}=1.07, \mathrm{SD}=.66)$ and paper-based letters $(\mathrm{M}=1.32, \mathrm{SD}=.33), \mathrm{t}(54)$ $=-2.50, \mathrm{p}<0.05$ ). The magnitude of the difference in the means was moderate (eta square $=.04$ ) and type of writing had only 4 percent of variance in the use of conjunctions.

Moreover, this test has been conducted for the use of references in electronic mails and paper-based letters. The significance of difference reported for the use of references in electronic mails $(\mathrm{M}=1.13, \mathrm{SD}=.56)$ and paper-based letters $(\mathrm{M}=1.24, \mathrm{SD}=.41)$ was $\mathrm{t}(54)=-1.11, \mathrm{p}>0.05)$. The magnitude of the difference in the means was small (eta square $=.01)$ and type of writing had only 1 percent of variance in the use of references. The results are presented in Table 2. 
TABLE 2.

PAIRED-SAMPLE T-TEST FOR THE USE OF CONJUNCTIONS AND REFERENCES IN ELECTRONIC MAILS AND PAPER-BASED LETTERS

\begin{tabular}{|c|c|c|c|c|c|c|c|c|c|}
\hline & & \multicolumn{5}{|c|}{ Paired Differences } & \multirow[b]{3}{*}{$\mathrm{t}$} & \multirow[b]{3}{*}{ df } & \multirow{3}{*}{$\begin{array}{l}\text { Sig. (2- } \\
\text { tailed) }\end{array}$} \\
\hline & & \multirow[b]{2}{*}{ Mean } & \multirow{2}{*}{$\begin{array}{l}\text { Std. } \\
\text { Deviation }\end{array}$} & \multirow{2}{*}{$\begin{array}{l}\text { Std. Error } \\
\text { Mean }\end{array}$} & \multicolumn{2}{|c|}{$\begin{array}{l}95 \% \text { Confidence } \\
\text { Interval of the } \\
\text { Difference }\end{array}$} & & & \\
\hline & & & & & Lower & Upper & & & \\
\hline Pair 1 & $\begin{array}{l}\text { Conjunctions in electronic } \\
\text { mails - Conjunctions in } \\
\text { paper-based letters }\end{array}$ & -.25000 & .73401 & .09989 & -.45035 & -.04965 & -2.503 & 53 & .015 \\
\hline Pair 2 & $\begin{array}{l}\text { References in electronic } \\
\text { mails - References in paper- } \\
\text { based letters }\end{array}$ & -.10741 & .70627 & .09611 & -.30018 & .08537 & -1.118 & 53 & .269 \\
\hline
\end{tabular}

Moreover, the researchers analyzed and compared the frequency of the use of different types of conjunctions, i.e. coordinating, correlative and transitional conjunctions and references i.e. anaphoric, exophoric and cataphoric. Table 3 tabulates the frequency of the use of three types of conjunctions in electronic mails and paper-based letters. As it is evident from this table, coordinating conjunctions are the most common conjunctions in both types of letters irrespective of their mood of presentation. In other words, $56 \%$ of conjunctions in electronic mails and $55 \%$ of them in paper-based letters are considered as coordinating conjunctions.

TABLE 3.

FREQUENCY OF THE USE OF DIFFERENT CONJUNCTIONS IN ELECTRONIC MAILS AND PAPER-BASE LETTERS

\begin{tabular}{|l|l|l|}
\hline $\begin{array}{l}\text { Types of } \\
\text { conjunctions }\end{array}$ & Electronic mails & Paper-based letters \\
\hline Coordinating & $\mathbf{5 6 \%}$ & $\mathbf{5 5 \%}$ \\
\hline Correlative & $13 \%$ & $\mathbf{2 1 \%}$ \\
\hline Transitional & $\mathbf{3 1 \%}$ & $\mathbf{2 4 \%}$ \\
\hline Total & $\mathbf{1 0 0 \%}$ & $\mathbf{1 0 0 \%}$ \\
\hline
\end{tabular}

Besides, the researchers investigated the type of references with regard to their frequency in both types of writings. As it is indicated in Table 4, anaphoric references are the most common references in electronic mails and paper-based letters. That is, respectively, $73 \%$ and $42 \%$ of the references are allocated to anaphoric references which show a high frequency of this reference type in both sorts of writing.

TABLE 4.

FREQUENCY OF THE USE OF DIFFERENT REFERENCES IN ELECTRONIC MAILS AND PAPER-BASE LETTERS

\begin{tabular}{|l|l|l|}
\hline Types of references & Electronic mails & Paper-based letters \\
\hline Anaphoric & $\mathbf{7 3 \%}$ & $\mathbf{4 2 \%}$ \\
\hline Exophoric & $12 \%$ & $\mathbf{2 3 \%}$ \\
\hline Cataphoric & $15 \%$ & $35 \%$ \\
\hline Total & $100 \%$ & $100 \%$ \\
\hline
\end{tabular}

\section{Discussion AND CONCLUSION}

Significant achievements in the application of CALL motivate teachers all around the world to use computers and electronic devices in the field of language learning. However, it is not an easy task to substitute this technology based learning and more specifically writing, with the conventional methods. The primary issue in this study was to compare electronic mails and paper-based letters in terms of the frequency of use of conjunction.

Conjunctions bring unity to the task of writing; it is a good idea to investigate such cohesive markers in the two mediums of writing. As the result shows there was a significant difference in the use of conjunctions in both groups; it was shown that the mean score for the use of conjunctions in paper-based letters were higher than the number of such cohesive ties in electronic mails. This may indicate a need to motivate learners to use more connectors to get better cohesion in the electronic texts. In other words, teachers are responsible to aware their learners of the use of conjunctions in electronic mails.

Besides, the same mean relationship has been achieved for the use of references in the two mediums. It was presented that the mean number of references were lower in electronic mails. Although there was a mean variation, the difference was not significant in the use of references.

With regard to the type of conjunctions, the participants' writings (both electronic and paper-based) presented similarities. The same results have been obtained for the use of references. That is to say, the 54 participants' letters showed similar rankings for the use of references. In the two medium, anaphoric references were used more than cataphoric references. Also, exospheric references were the least frequent references in the electronic mails and paperbased letters. These findings are motivating since it shows that the learners may use similar processes in the use of conjunctions in both electronic mails and paper-based letters. 


\section{REFERENCES}

[1] Biesenbach-Lucas, S., Meloni, C., \& Weasenforth, D. (2000). Use of cohesive features in ESL students' e-mail and wordprocessed texts: A comparative study. Computer Assisted Language Learning. 13(3) 221-237.

[2] Biesenbach-Lucas, S. \& Weasenforth, D. (2001). E-mail and word-processing in the ESL classroom: How the medium affects the message. Language learning and Technology. 5(1) 135-165.

[3] Danet, $\quad$ B. (2002). The language of email. $\quad$ Retrieved from http://www.europhd.it/html/_onda02/04/ss8/pdf_files/lectures/Danet_email.pdf (accessed 20/4/2013).

[4] Er, E. (1993). text analysis and diagnostic assessment. (229-240). In A. Burns, \& C. Coffin, (Eds.), Analyzing English in a global contexts: a reader. London: Routledge.

[5] Halliday, M.A.K. \& Hassan, R. (1976). Cohesion in English. London: Longman

[6] Lightfoot, J. M. (2006). A comparative analysis of e-mail and face-to-face communication in an educational environment. Internet and Higher Education 9 (2006) 217-227.

[7] McCarthy, M. (1991). Discourse analysis for language teachers. Cambridge: Cambridge University Press.

[8] Nunan, D. (1993). Introducing discourse analysis. Penguin group: England.

[9] Nunan, D. (1999). Second language teaching and learning. Heinle \& Heinle Publishers: Boston.

[10] Richards, J. C., Platt, J., \& Platt, H. (1992). Dictionary of language teaching and applied linguistics. London: Longman.

[11] Salkie, R. (1995). Text and discourse analysis. London: Routledge.

[12] Sattar, S. \& Nahrkhalaji, S. S. (2012). The role of email activities in EFL writing classes. Retrieved from research.iaun.ac.ir/pd/sattar737/pdfs/PaperC_6332.pdf (accessed 20/4/2013).

[13] Seow, A. (1995). How to respond to student writing. Teaching and Learning, 17(1), 78-85.

[14] Slutsky, J.M. \& Sardegna, V.G. (2010). Web-based writing materials that promote non-native business students' autonomous learning. Retrieved from http://businesscommunication.org/wp-content/uploads/2011/04/ABC-2010-23.pdf (accessed $16 / 4 / 2013)$

[15] Warschauer M. (1996). "Computer Assisted Language Learning: an Introduction". In Fotos S. (ed.) Multimedia language teaching, Tokyo: Logos International: 3-20.

Nader Assadi Aidinlou holds a PhD in Applied Linguistics from University Sains Malaysia and his MA. and BA. in Teaching English as a Foreign Language from Islamic Azad University, Tabriz Branch. As an academic member at the Department of English Language and Literature, Islamic Azad University, he is the Research Vice-chancellor and Head of the Graduate Department of English Language and Literature at Islamic Azad University, Ahar Branch. He has widely published and presented papers in different international journals and conferences and published the book "The ABC's of Functional Grammar" by Oxford Fajar. He is also an authorized translator for the Islamic Republic of Iran's Administration of Justice.

Elnaz Reshadi is a Ph.D. candidate in TEFL at Islamic Azad University, Ahar Branch in Iran. She has been an instructor at Payam-Noor University since 2009. Her major research interests include learner differences, academic writing, cooperative assessment and critical discourse analysis. 